\title{
QUEBRADA DE LOS BURROS. LOS PRIMEROS PESCADORES DEL LITORAL PACÍFICO EN EL EXTREMO SUR PERUANO*
}

\section{QUEBRADA DE LOS BURROS. FIRST FISHERMEN OF THE SOUTH PACIFIC COAST IN THE FAR SOUTH OF PERU}

\author{
Danièle Lavallée ${ }^{1}$, Michèle Julien ${ }^{2}$, Philippe Béarez ${ }^{3}$, Aldo Bolaños ${ }^{4}$, Matthieu Carré \\ Alexandre Chevalier ${ }^{6}$, Tania Delabarde ${ }^{7}$, Michel Fontugne ${ }^{8}$, Cecilia Rodríguez-Loredo ${ }^{9}$, \\ Laurent Klaric ${ }^{10}$, Pierre Usselmann ${ }^{11}$ y Marian Vanhaeren ${ }^{12}$
}

\begin{abstract}
Las excavaciones en la Quebrada de los Burros, en el litoral de Tacna (Perú), han descubierto un campamento de pescadores y recolectores de moluscos (QLB) ocupado entre 10.000 y 6.000 a.p., durante el Holoceno Temprano y Medio. Seis niveles sucesivos de ocupación han sido excavados por decapado, cada uno contando con aterrazamientos del piso, fogones, áreas de actividad diversas y acumulaciones de desechos alimenticios marinos, mezclados con restos de fauna terrestre. El conjunto de estos desperdicios demuestra que, desde el inicio de la ocupación, los ocupantes dominaban perfectamente el medio marítimo pero explotaban también las lomas. Los instrumentos de piedra y hueso atestiguan un ajuar muy sofisticado de pesca, recolección y caza. Dos fases de ocupación fueron singularizadas, la primera durante el Holoceno Temprano (ca. 10.000 a 7.000 a.p.), la segunda durante el Holoceno Medio (ca. 7.000 a 6.000 a.p.). Los análisis efectuados sugieren para la primera fase una sucesión de ocupaciones breves y posibles contactos con las tierras altas y, al contrario, una ocupación más intensa y casi permanente a lo largo del año para la segunda fase, durante la cual las materias primas líticas proceden todas de sectores cercanos. Una estrecha relación con sitios chilenos Chinchorro está confirmada.
\end{abstract}

Palabras claves: Arcaico, Chinchorro, estacionalidad, Holoceno antiguo, Holoceno Medio, pesca y recolección, otolitos, esclerocronología, Tacna.

Research works at Quebrada de los Burros evidenced an Archaic settlement on the littoral of Tacna (Peru). This campsite of fishermen and shell-gatherers (QLB) has been occupied during Early and Middle Holocene, between 10,000 and 6,000 BP. Broad horizontal excavations revealed six successive occupation levels, with living floor layouts, hearths, specialized activity areas and accumulations of food waste of marine origin mixed with bones of terrestrial fauna. As a whole, these remains indicate that, since the beginning, the inhabitants relied intensively on ocean resources but they also exploited the lomas. Lithic tools and bone instruments attest a sophisticated equipment for fishing, gathering and hunting. Two phases of occupation were characterized, the first during Early Holocene (ca. 10,000 to 7,000 BP), the second during Middle Holocene (ca. 7,000 to 6,000 BP). The analyses suggest, for the first phase, a succession of short occupations and possible contacts with high lands and, on the contrary, a more intensive occupation, nearly all the year round, for the second, during which raw lithic materials came from nearby areas. A close relation with Chilean sites Chinchorro is confirmed.

Key words: Archaic, Chinchorro, seasonality, Early Holocene, Mid Holocene, fishing and collect, otoliths, sclerochronology, Tacna.

* Un texto preliminar de este artículo fue presentado en el $53^{\circ}$ Congreso Internacional de Americanistas, Simposio "El período Arcaico en los Andes Sur Centrales: Tradiciones culturales e innovaciones tecnológicas”, Ciudad de México, 19 al 24 de julio de 2009. Este manuscrito fue evaluado por investigadores externos y editado por Luis Flores Blanco y Mark S. Aldenderfer, en su calidad de editores invitados de la Revista.

1 Archéologie des Amériques, UMR 8096, Maison René Ginouvès, Nanterre, France. daniele.lavallee@ wanadoo.fr

2 Archéologie et Sciences de l'Antiquité, UMR 7041, Maison René Ginouvès, Nanterre, France. michele.julien@ mae.u-paris10.fr

3 Archéologie, Histoire des Sociétés humaines et des peuplements animaux, UMR 5197, Museum national d'Histoire naturelle, Paris, France. bearez@mnhn.fr

$4 \quad$ Universidad Nacional Mayor San Marcos, Lima, Perú. aldofernando@yahoo.com

5 Institut des Sciences de 1'Evolution, UMR 5554, Université Montpellier2, France. matthieu.carre@univ-montp2.fr

6 Institut Royal des Sciences Naturelles, Bruxelles, Belgique. alexandre.chevalier@atelier.cx

7 Instituto Francés de Estudios Andinos, Quito, Ecuador. tdelabarde@ hotmail.com

8 Laboratoire des Sciences du Climat et de l'Environnement, UMR 1572, Gif-sur-Yvette, France. michel.fontugne@ 1sce.ipsl.fr

93 boulevard E. Mounier, 35700 Rennes, France. cecilia.rodriguez-loredo@ univ-rennes1.fr

10 Préhistoire et Technologie, UMR 7055, Maison René Ginouvès, Nanterre, France. laurent.klaric@ mae.u-paris10.fr

11 Maison de la Géographie, UMR 6012, Montpellier, France. pierre.usselmann@ wanadoo.fr

12 Archéologie et Sciences de l'Antiquité, UMR 7041, Maison René Ginouvès, Nanterre, France. marianne.vanhaeren@mae.u-paris10.fr 


\section{El Sitio en su Marco Ambiental, Pasado y Actual}

La Quebrada de los Burros (QLB), que recorrimos en 1994 durante una temporada de prospecciones sistemáticas realizada en el departamento de Tacna, es un valle corto y estrecho del desierto costero $\left(18^{\circ}\right.$ $1^{\prime} \mathrm{S}-70^{\circ} 50^{\prime} \mathrm{W}$ ) (Figura 1). La parte inferior de la QLB está ocupada por un cono aluvial árido, por ambas partes, del cual alternan bahías arenosas y recortados acantilados rocosos. En la parte media de su curso, aproximadamente a un kilómetro y medio de la línea de costa, la quebrada ofrece un muy ligero pero permanente escurrimiento superficial de agua, cuyo lecho está fuertemente recortado entre abruptas escarpaduras rocosas. Más arriba de esta garganta, a partir de 150 metros de altura, el valle se ensancha y conforma una pequeña cuenca con un relleno aluvial. Aquí se sitúa el lugar de nuestras excavaciones arqueológicas (Figura 2).

La disposición geográfica de la QLB, orientada $\mathrm{S}-\mathrm{N}$, favorece de manera óptima la penetración de los vientos alisios cargados de humedad durante el invierno, entre junio y octubre. La condensación directa sobre las vertientes, especialmente entre 750 y 850 metros de altura, origina el desarrollo de una vegetación de lomas, que favorece temporalmente la presencia de numerosas aves y animales terrestres (desde moluscos, batracios y pequeños mamíferos, hasta grandes herbívoros como guanacos y cérvidos). Con la excepción de las lomas, el medio es desértico. Pero las aguas oceánicas contienen una de las más ricas biomasas del mundo. La franja costera está bañada por la corriente de Humboldt,

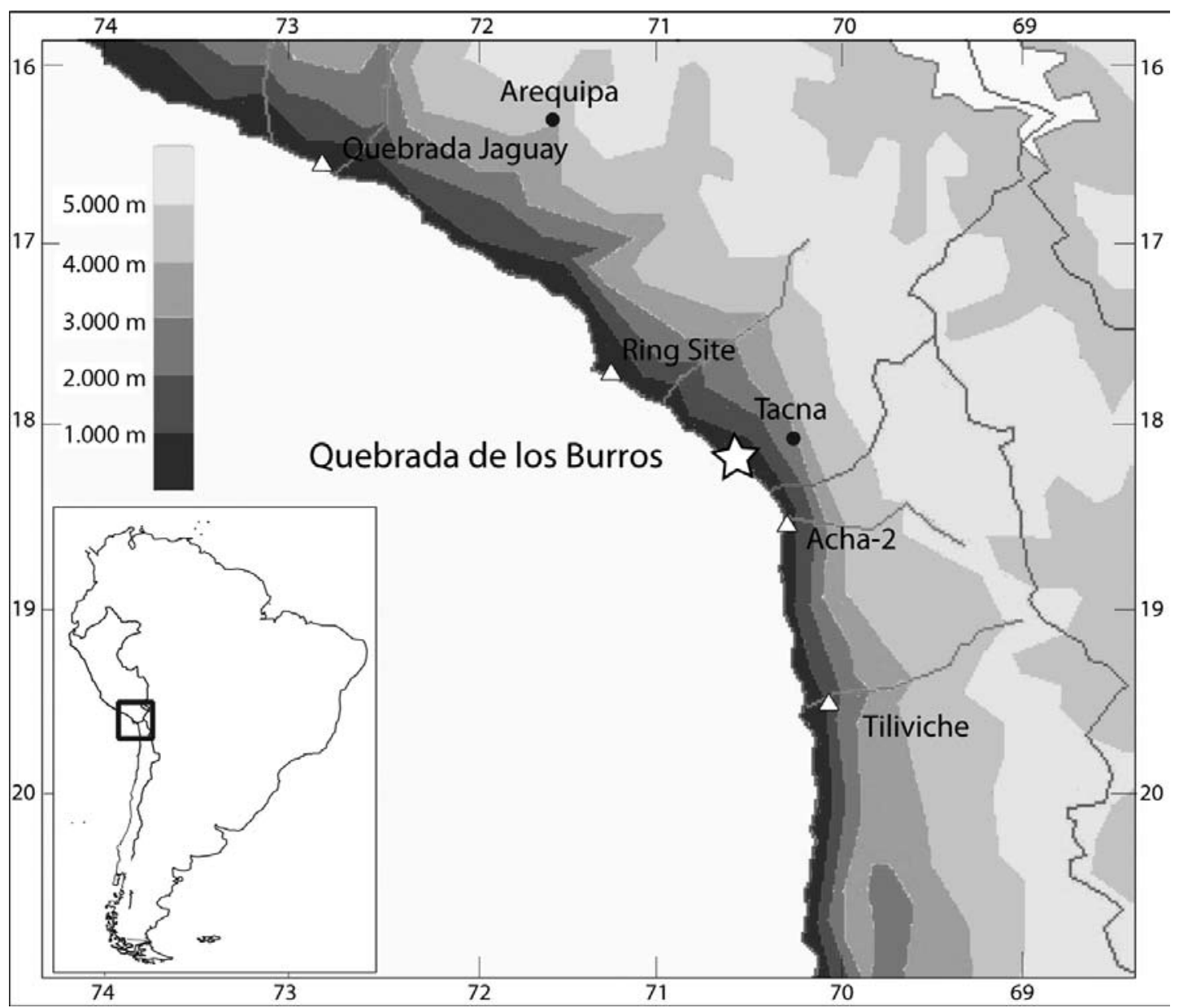

Figura 1. Situación geográfica de la Quebrada de los Burros. Los triángulos blancos indican los emplazamientos de los sitios arqueológicos más significativos del periodo Arcaico Temprano.

Geographical location of the Quebrada de los Burros. The white triangles indicate the emplacement of the most significant archaeological sites of the Early Archaic Period. 


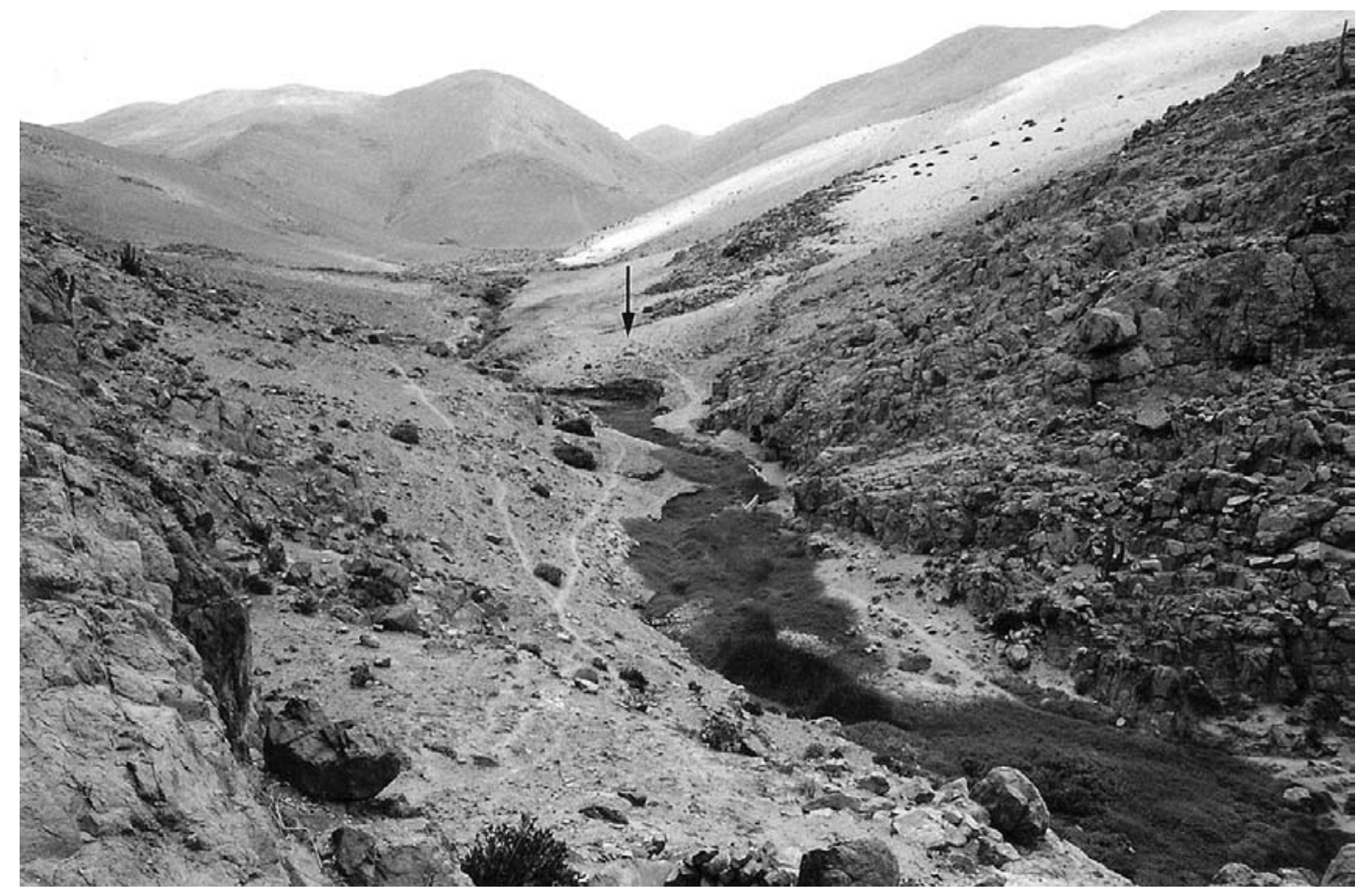

Figura 2. Parte media de la Quebrada de los Burros, vista desde río abajo. La flecha indica el emplazamiento de la excavación. Middle part of the Quebrada de los Burros, seen from downstream. The arrow indicates the emplacement of the excavation.

caracterizada por un traslado hacia el norte, bajo el efecto de los alisios, de las aguas superficiales tibias que son reemplazadas por subidas de aguas frías profundas (upwelling). Estas aguas ricas en elementos nutritivos acogen una fauna marina superabundante. Sin embargo, el upwelling puede ser alterado por los eventos El Niño que se manifiestan de manera episódica y con intensidades variables a lo largo de las costas peruanas y chilenas. Componente regional del fenómeno ENSO (El Niño Southern Oscillation), este evento corresponde a una debilitación de los alisios y a una elevación correlativa de la temperatura de las aguas superficiales, con una disminución de los aportes nutritivos y una bajada de la termoclina. Las consecuencias pueden ser devastadoras: en el océano, el enrarecimiento o la desaparición de los peces de aguas frías, la muerte consecutiva de miles de aves y mamíferos marinos; sobre la tierra, lluvias torrenciales, huaycos y la ampliación de una cobertura vegetal normalmente limitada a los sectores de lomas.

Estos aspectos ambientales jugaron un papel esencial en la historia de la ocupación humana. Existen a lo largo de la QLB varios perfiles naturales expuestos por el encajonamiento relativamente reciente del riachuelo, que presentan una alternancia de acumulaciones de conchas marinas (aportes antrópicos) y de capas de sedimentos finos o gruesos. Uno de estos perfiles, de más de $2 \mathrm{~m}$ de altura, expone una serie de niveles turbosos oscuros y conteniendo a menudo conchas marinas, que alternan con estratos naturales de arenas o gravas. La cumbre y la base del conjunto las conforman dos gruesas avenidas de lavas torrenciales. Según Michel Fontugne y Pierre Usselmann, los niveles turbosos representan cada uno un período húmedo durante el cual el fondo del valle estaba ocupado por un estancamiento de agua conformando una pequeña laguna o un pantano. Fechados radiocarbónicos procesados sobre muestras orgánicas ubican el conjunto de los sucesivos depósitos turbosos entre $\sim 9.640$ y $\sim 3.391$ cal. a.p. (edad más probable o approximate mid-point). Muy notable es la casi-permanencia, durante más de seis mil años, de un clima relativamente calmo y húmedo, ligado a neblinas invernales muy densas, aunque interrumpido a veces por episodios torrenciales de menor potencia. Por otra parte, según los mismos 
autores, los dos flujos en la base y la cumbre podrían resultar de eventos El Niño acontecidos, el primero hacia 8.980 cal. a.p. y el más reciente después de 3.380 cal. a.p. (Fontugne et al. 1999; Usselmann et al. 1999).

\section{El Yacimiento Arqueológico}

Excavaciones intensivas en el área mediante sucesivos decapados de los pisos de ocupación se iniciaron en 1996 en la parte media de la QLB, en la vertiente izquierda, donde sondeos preliminares habían evidenciado la presencia de depósitos arqueológicos estratificados. El yacimiento se ubica a 170 msm y dos kilómetros de la línea actual de la costa, situación que no debe haber cambiado mucho desde los últimos diez mil años. En efecto, debido a la naturaleza abrupta del litoral y a la estrechez de la plataforma continental (shelf) en este sector, la subida postglacial del océano no afectó sino de manera poco sensible el trazado de la costa.

En diez temporadas anuales de excavación y sobre aproximadamente dos metros de espesor, seis niveles sucesivos de ocupación fueron evidenciados (N7 a N2, del más antiguo al más reciente. El nivel N1 corresponde al suelo superficial de arena suelta y N8 al nivel de base estéril). El total de la superficie contigua excavada alcanza $150 \mathrm{~m}^{2}$. Las ocupaciones se suceden entre $\sim 9.581$ y $\sim 6.839$ cal. a.p. (Figura 3) y una única pero larga interrupción, materializada en la estratigrafía por un estrato de arena estéril, se observa en la sucesión de los fechados radiocarbónicos entre los niveles N4 y N3 (Tabla 1 y Figura 4).

Todos los niveles están conformados por importantes acumulaciones de restos de fauna alimenticia de origen marino y terrestre, asociadas con estructuras de varios tipos, material lítico tallado e implementos de hueso o concha. El conjunto corresponde a una instalación de pescadores y recolectores de moluscos que testimonia desde el inicio una maestría perfecta de explotación del medio marítimo. El análisis de los depósitos demostró sin embargo, entre los niveles del Holoceno Temprano N7-N6N5-N4 ( 9.581 a 8.637 cal. a.p.) y los niveles del Holoceno Medio N3-N2 ( 7.360 a $\sim 6.839$ cal. a.p.), diferencias notables, tanto en la naturaleza de los recursos explotados como en el equipo técnico, en la duración y en el ritmo de las ocupaciones.

En comparación de los primeros artículos publicados (Lavallée, Béarez et al. 1999; Lavallée,
Julien et al. 1999; Lavallée 2003, 2005), nuestro cuerpo de datos ha sido aumentado de manera significativa, la profundidad cronológica de la ocupación del campamento evaluada en su totalidad y las interpretaciones afinadas. De tal manera que la interesante síntesis propuesta por Daniel Sandweiss (2003), que limita la ocupación de QLB al Holoceno Medio, merecería una revaluación.

\section{Los Recursos y su Explotación}

Lo esencial de la alimentación procedía del océano. Los restos más visibles son las conchas de moluscos, pero la contribución más importante era la de los peces. Recuperados por tamizado con malla $1 / 8$ ", debido a su tamaño muy reducido y su fragilidad, sus restos óseos representan, cuando la ocupación alcanza su mayor densidad (N3-N2), entre 15 y 40 individuos por $\mathrm{m}^{2}$ sobre 15 a $20 \mathrm{~cm}$ de espesor (lo que corresponde a una pasada de decapado).

Más de treinta especies de peces óseos así como varios selacios fueron identificados por Philippe Béarez, con un total de 11.498 restos determinados hasta entonces (Tabla 2). Este total representa el conjunto analizado de osamentas y otolitos de los niveles N2 a N6. A lo largo de la ocupación, los Sciaenidae dominan con una especie principal, la lorna (Sciaena deliciosa), que representa siempre más de un $50 \%$ cualquiera que sea el nivel, con un promedio de $56 \%$ del conjunto. El espectro fáunico reconstituido a la luz de la etoecología de las especies pone de manifiesto que los fondos arenosos y el ámbito pelágico favorecieron su captura (Figura 5). En efecto, junto a los Sciaenidae se encuentran especies pelágicas como el jurel (Trachurus murphyi), el machete (Ethmidium maculatum) y el bonito (Sarda chiliensis). Los modelos osteométricos elaborados a partir de otolitos permitieron reconstruir el tamaño medio de Sciaena deliciosa, de $26 \mathrm{~cm}$ para 375 gramos, valor constante en los distintos niveles, pero Cilus gilberti y Sciaena wieneri, otras especies de la misma familia, a menudo están representadas por individuos de $1 \mathrm{~m}$ o más de longitud para un peso de alrededor de $30 \mathrm{~kg}$ (Béarez 2000; Béarez en Lavallée y Julien 2003:43-48).

Las capturas podían efectuarse desde la orilla o desde un esquife. Según la forma de los histogramas de importancia y la naturaleza de los aparejos de pesca encontrados, la pesca se efectuaba con cuerda o con ayuda de redes, permitiendo la captura en 
Perfil Norte

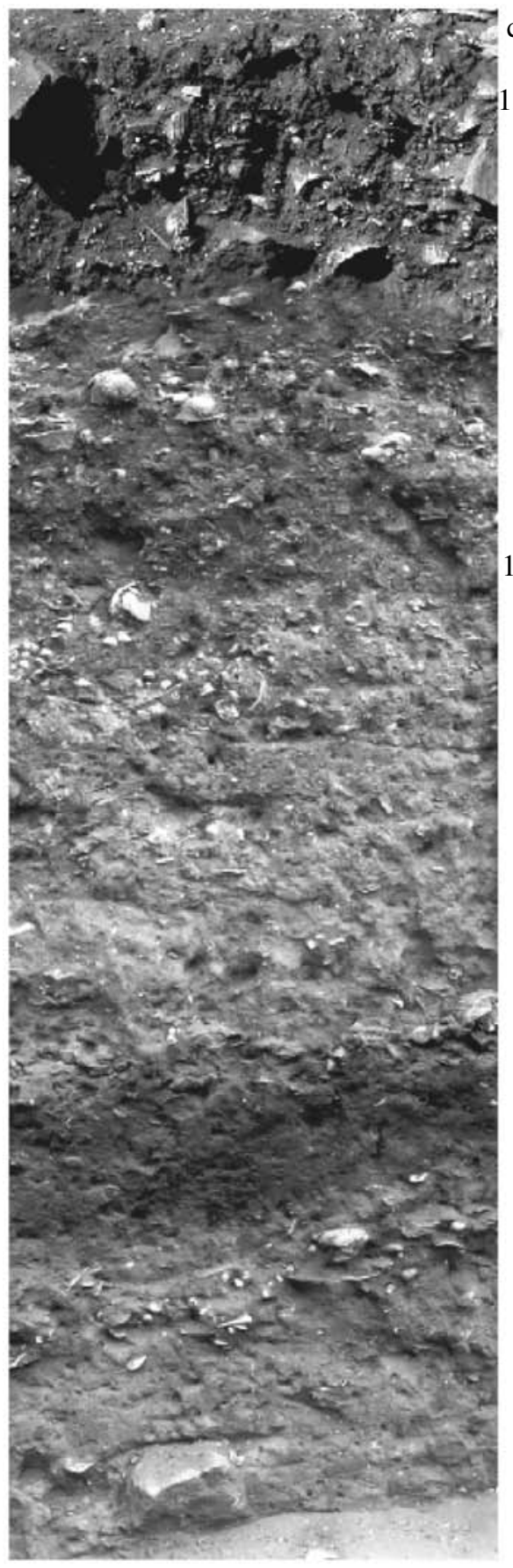

\section{CAL Y BP}

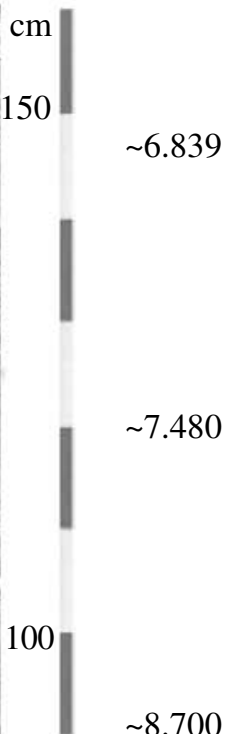

$\sim 9.129$

$\sim 9.179$

$\sim 9.411$
QLB

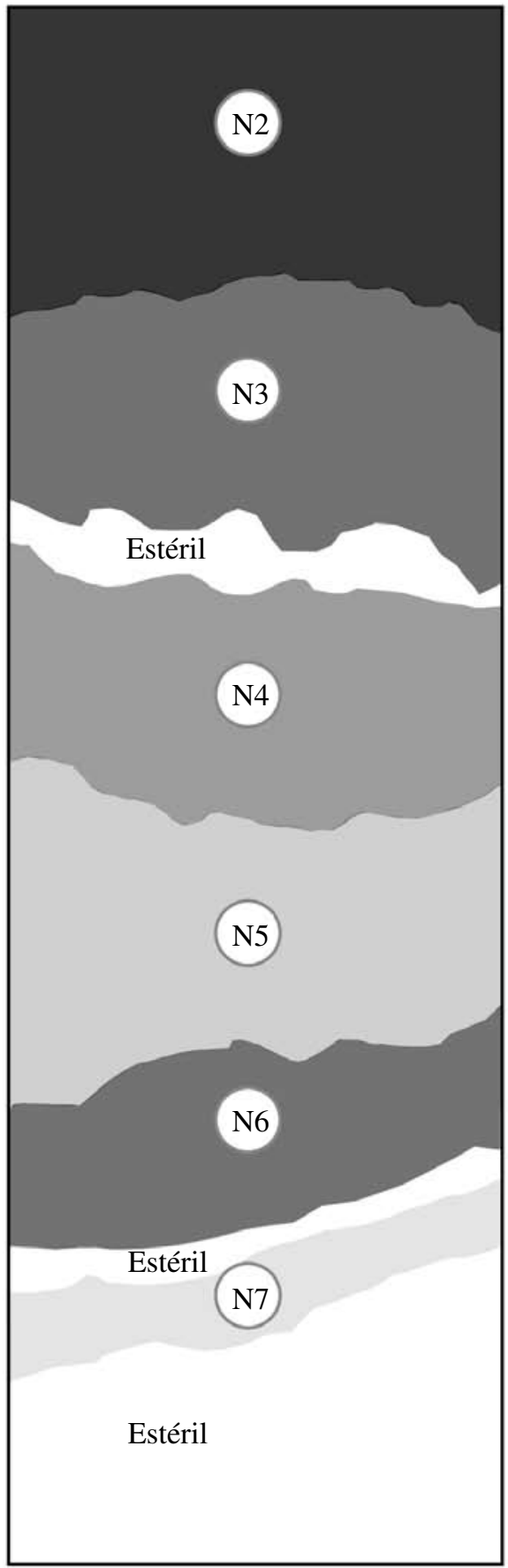

Figura 3. Cronoestratigrafía del campamento arcaico QLB. QLB archaic camp chronostratigraphy. 
Tabla 1. Fechados 14C del campamento arcaico QLB.

$14 C$ dating of Archaic camp QLB.

\begin{tabular}{ccccccccc}
\hline Nivel & muestra & material & d13C & 14 C BP & Ed+prob. & Cal BP & Cal BC & Ref. Lab. \\
\hline N2 & a & carbón & $-25,3$ & $6050 \pm 80$ & 6839 & 6639,7155 & 4689,5209 & GifA-99341 \\
N2 & b & carbón & $-27,4$ & $6090 \pm 110$ & 6895 & 6636,7238 & 4688,5288 & GifA-100142 \\
N2 & c & carbón & 25,9 & $6260 \pm 35$ & & & & SacA 7586 \\
N2 & d & carbón & & $6460 \pm 60$ & 7337 & 7176,7432 & 5228,5482 & $10623 /$ GifA-972 \\
N2 & e & carbón & $-17,9$ & $6520 \pm 90$ & 7373 & 7177,7564 & 5227,5614 & $11284 /$ GifA-995 \\
N2 & f & carbón & & $6630 \pm 70$ & 7480 & 7325,7583 & 5594,5342 & $10625 / G i f A-972$ \\
N3 & a & carbón & $-25,9$ & $6415 \pm 80$ & 7291 & 7028,7433 & 5078,5483 & Gif-11735 \\
N3 & b & carbón & $-25,3$ & $6430 \pm 80$ & 7306 & 7030,7461 & 5080,5511 & GifA-100346 \\
N3 & c & carbón & $-23,7$ & $6500 \pm 80$ & 7359 & 7174,7506 & 5224,5556 & GifA-100347 \\
N4 & a & carbón & 28,4 & $7390 \pm 35$ & & & & SacA 7591 \\
N4 & b & carbón & $-16,5$ & $7880 \pm 90$ & 8637 & 8424,8977 & 6474,7027 & GifA-100342 \\
N4 & c & carbón & -26 & $7970 \pm 140$ & 8774 & 8419,9122 & 6469,7172 & GifA-100344 \\
N4 & d & carbón & $-25,3$ & $7980 \pm 90$ & 8779 & 8548,9009 & 6598,7059 & GifA-100345 \\
N5 & & carbón & & $8220 \pm 90$ & 9129 & 8779,9427 & 6829,7477 & GifA-102445 \\
N6 & & carbón & 23,9 & $8400 \pm 40$ & & & & SacA 10218 \\
N7 & a & carbón & & $8460 \pm 80$ & 9411 & 9141,9540 & 7191,7590 & GifA-102446 \\
N7 & b & carbón & $-12,3$ & $8675 \pm 40$ & & & & SacA 7589 \\
\hline
\end{tabular}

Tabla 2. Lista de las especies de peces identificadas en QLB.

List of fish species identified in $Q L B$.

\begin{tabular}{|c|c|c|c|c|}
\hline Familia & Especie & NISP & $\%$ & Medio \\
\hline Chondrichthyes & tiburones y rayas & 40 & 0,35 & \multirow{8}{*}{ Fondos arenosos } \\
\hline \multirow{2}{*}{ Sciaenidae } & Sciaena deliciosa & 6.428 & 55,91 & \\
\hline & Cilus gilberti & 328 & 2,85 & \\
\hline Ariidae & Galeichthys peruvianus & 27 & 0,23 & \\
\hline Paralichthyidae & Paralichthys adspersus & 13 & 0,11 & \\
\hline \multirow{3}{*}{ Sciaenidae } & Sciaena wieneri & 5 & 0,04 & \\
\hline & Cynoscion analis & 3 & 0,03 & \\
\hline & Paralonchurus peruanus & 1 & 0,01 & \\
\hline Carangidae & Trachurus murphyi & 1.573 & 13,68 & \multirow{11}{*}{ Zona pelágica } \\
\hline Clupeidae & Ethmidium maculatum & 934 & 8,12 & \\
\hline Haemulidae & Isacia conceptionis & 613 & 5,33 & \\
\hline Scombridae & Sarda chiliensis & 463 & 4,03 & \\
\hline Clupeidae & Sardinops sagax & 299 & 2,60 & \\
\hline Scombridae & Scomber japonicus & 161 & 1,40 & \\
\hline Engraulidae & Engraulis ringens & 127 & 1,10 & \\
\hline Scombridae & Katsuwonus pelamys & 4 & 0,03 & \\
\hline Centrolophidae & Seriolella violacea & 2 & 0,02 & \\
\hline Carangidae & Seriola lalandi & 1 & 0,01 & \\
\hline Gempylidae & Thyrsites atun & 1 & 0,01 & \\
\hline Cheilodactylidae & Cheilodactylus variegatus & 310 & 2,70 & \multirow{13}{*}{$\begin{array}{c}\text { Fondos rocosos y } \\
\text { macroalgas }\end{array}$} \\
\hline Haemulidae & Anisotremus scapularis & 70 & 0,61 & \\
\hline Gobiesocidae & Sicyases sanguineus & 23 & 0,20 & \\
\hline Serranidae & Paralabrax humeralis & 19 & 0,17 & \\
\hline Sciaenidae & Cheilotrema fasciatum & 19 & 0,17 & \\
\hline Blenniidae & Scartichthys gigas & 9 & 0,08 & \\
\hline Labrisomidae & Auchenionchus microcirrhis & 9 & 0,08 & \\
\hline Serranidae & Acanthistius pictus & 5 & 0,04 & \\
\hline Pinguipedidae & Pinguipes chilensis & 3 & 0,03 & \\
\hline Aplodactylidae & Aplodactylus punctatus & 3 & 0,03 & \\
\hline Kyphosidae & Girella laevifrons & 3 & 0,03 & \\
\hline Labrisomidae & Labrisomus philippii & 2 & 0,02 & \\
\hline Total & & 11.498 & 100 & \\
\hline
\end{tabular}


OxCal v4.05 Bronk Ramsey (2007); r.5 IntCal04 atmospheric curve (Reimer et al. 2004)

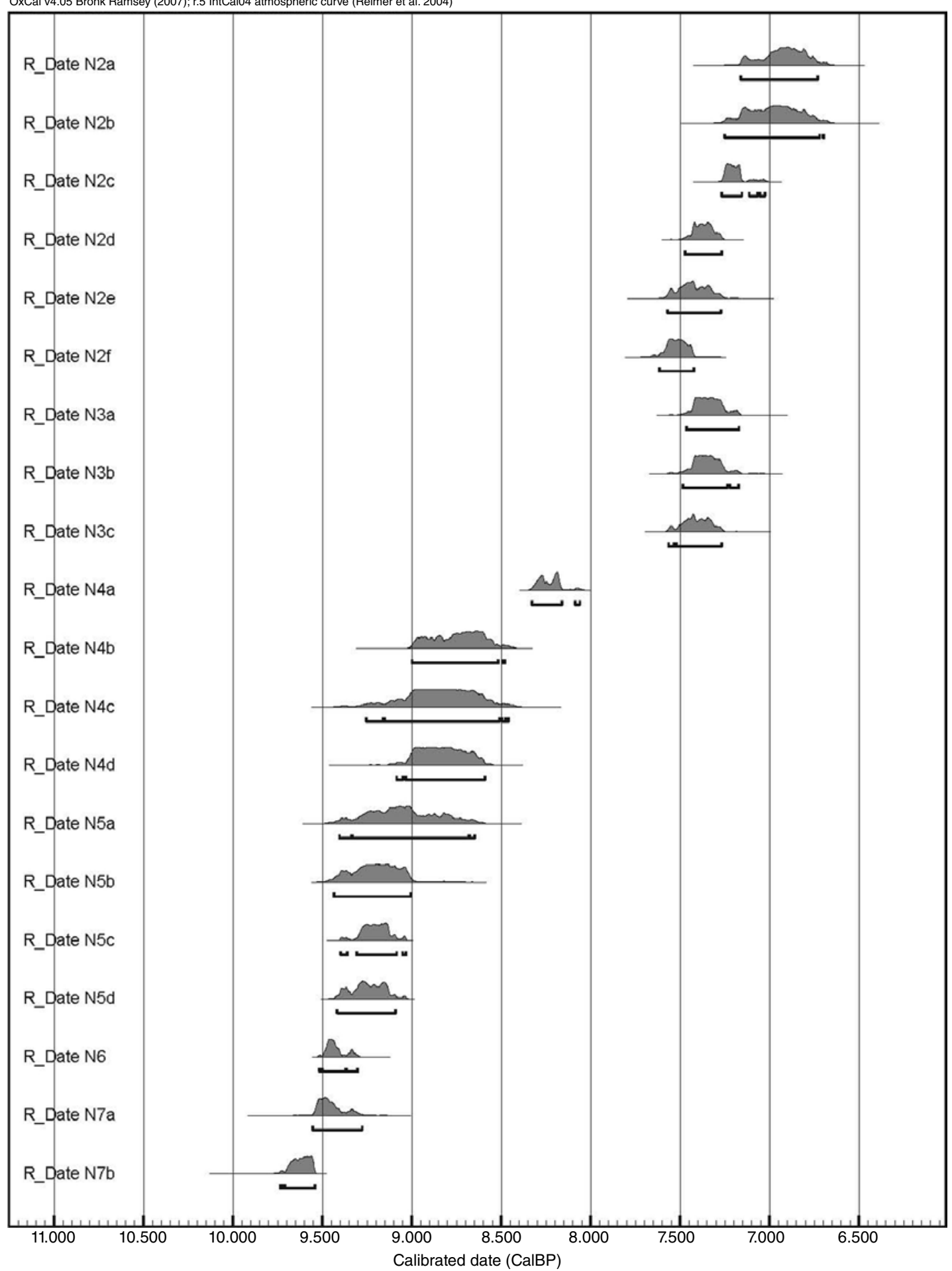

Figura 4. Curvas de calibración de los fechados BP (Reimer et al. 2004).

Calibration curves dated BP (Reimer et al. 2004). 
Ecología de las especies capturadas

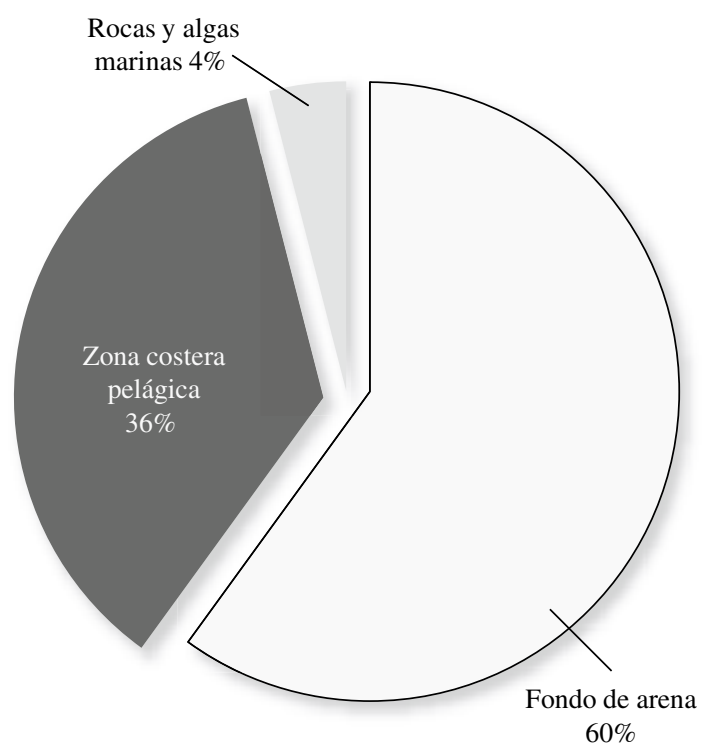

Figura 5. Ambientes frecuentados por las especies de peces capturadas.

Environments frequented by fish species caught.

gran número. La imagen elaborada por el estudio de los otolitos no permite, en cambio, evaluar la proporción de los pequeños peces pelágicos (anchoveta, sardina) necesariamente capturados con red. Esa proporción no podrá ser apreciada sino por el análisis (no terminado) del material óseo resultante de un tamizado más fino. Las capturas son relativamente homogéneas a través del tiempo, pero se puede notar en los niveles profundos $\mathrm{N} 6 \mathrm{y}$ N5 la presencia de una fauna de aguas más frías, con algunos especímenes de trambollo (Auchenionchus microcirrhis), cojinoba (Seriolella violacea), sierra (Thyrsites atun). Al contrario, se identificaron en los niveles superiores $\mathrm{N} 3$ y N2 algunas especies de aguas calientes como el Scombridae pelágico Katsuwonus pelamys. Estas dos observaciones podrían ser el índice de un relativo recalentamiento de las aguas entre $\mathrm{N} 4$ y N3, lo que los análisis de otros materiales tienden a confirmar (véase infra).

La diversidad de los ambientes explotados está también evidenciada por la colecta de pequeños cangrejos Anomouros, esencialmente en los niveles profundos $\mathrm{N} 7$ hasta $\mathrm{N} 4$, de erizos y de una decena de especies de moluscos. Dos especies dominan en todos los niveles: el loco o chanque (Concholepas concholepas) y la macha (Mesodesma donacium). Provienen, la primera, de las rocas infralitorales e intermareales donde se encuentra hasta $5 \mathrm{~m}$ de profundidad, y la segunda, de las playas de arena donde vive enterrada a poca profundidad. Se encuentran también aunque en menor cantidad grandes choros o "choros-zapato" (Choromytilus chorus) que miden hasta $22 \mathrm{~cm}$ de largo, hoy en día casi desaparecidos de las aguas costeras de la región, y pequeños choros o "choritos de playa" (Perumytilus purpuratus). Por fin, algunas especies minoritarias están también presentes a lo largo de la ocupación (Tegula atra, Fissurella sp., Protothaca taca, Eurhomalea rufa, y numerosos Chitonidae).

Algunas cifras dan una idea de la cantidad total de los restos testáceos (conchas enteras y fragmentos $>3 \mathrm{~cm}$ ) recogidos en la excavación, sobre una superficie variando de 110 a $150 \mathrm{~m}^{2}: 76.530$ en N3, 123.689 en N4, 138.344 en N5. Los moluscos constituyen, al igual que los peces, bioindicadores muy sensibles que reaccionan a una mínima variación de las condiciones de salinidad o temperatura, en función de las cuales las especies pueden migrar. Observamos a lo largo de la ocupación de la QLB una inversión de las frecuencias relativas de las dos especies mayoritarias. El porcentaje de Mesodesma donacium, que domina largamente en los niveles N7 y N6, va bajando paulatinamente a partir del nivel $\mathrm{N} 5$ mientras aumenta el de $C$. concholepas. La inversión se produce a partir de N3, cuando $C$. concholepas viene a ser mayoritaria (Figura 6). Si no se puede eliminar totalmente la hipótesis de una opción cultural aunque poco verosímil, tal inversión reflejaría con mayor probabilidad una modificación de orden climático o topográfico. En efecto, no se deben dejar de lado ni la hipótesis de una leve pero sensible modificación de la línea de costa, consecutiva a la subida postglaciar de las aguas oceánicas, que hubiera causado la desaparición de algunos sectores de playas abiertas próximas a la QLB, ni tampoco la posibilidad de una desaparición temporaria de la población de $M$. donacium a consecuencia de un evento ENSO.

Para cada una de las dos especies mayoritarias y en cada nivel hemos medido 200 conchas enteras, para apreciar si existen o no diferencias dimensionales entre los niveles (análisis en curso).

Conviene ser prudentes, pero una tercera categoría de indicios proporcionados por el análisis de las conchas fortalece la hipótesis de un cambio climático entre N4 y N3 (cuyos depósitos están separados por el estrato estéril sintomático de un período de abandono del lugar): la medida de los 


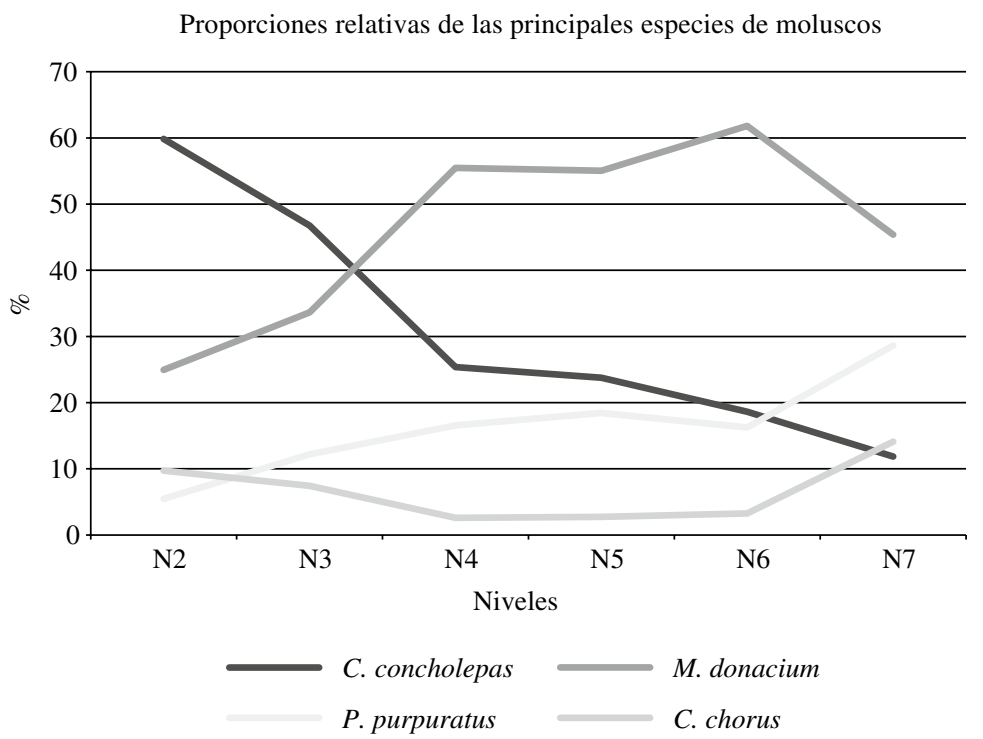

Figura 6. Frecuencia (en \%) de las especies de moluscos por nivel.

Frequency (in \%) of mollusc species level.

isótopos estables de oxígeno y carbono, realizada por Matthieu Carré sobre valvas arqueológicas de $M$. donacium procedentes de varios niveles de ocupación de la QLB, demuestra que, antes de 8.500 a.p., la temperatura oceánica estaba aproximadamente $3^{\circ}$ más fría y el upwelling más activo. Nuevos análisis están en curso sobre una mayor cantidad de valvas, lo que debería permitir una evaluación más fina y una mejor precisión cronológica.

\section{La fauna terrestre}

Todos los niveles arrojaron también una cantidad apreciable de restos óseos de fauna terrestre y de aves, a los cuales se deben agregar unos escasos restos de mamíferos marinos. A pesar de una tasa de fragmentación muy elevada, la que impide a menudo una determinación a nivel de género y menos aún de especie, Cecilia Rodríguez-Loredo logró determinar (con diversos grados de precisión) 24.408 restos, sobre un total de 25.265 analizados hasta la fecha para los seis niveles de ocupación, y sólo en una mitad de la superficie total excavada (Rodríguez-Loredo en Lavallée y Julien 2004:6773 , y comunicación personal 2009). Una cantidad importante de restos queda entonces en curso de análisis.

Se han determinado 636 restos de anfibios y reptiles, 8.258 de aves, 279 de mamíferos marinos
(Otaridae), 940 restos de herbívoros, 9 de carnívoros y 3.794 de roedores. A estos se agregan 2.461 restos clasificados como de "mamíferos mayores", 178 de "mamíferos menores" y 7.853 de "mamíferos indeterminados", una determinación más fina es imposible.

Parece fuera de duda que ciertos animales identificados no fueron consumidos ni tampoco cazados, pero su presencia testimonia el medio natural: así, los reptiles típicos del desierto circundante y los batracios (Bufo sp.) que testimonian la presencia de agua dulce cerca del campamento. Otros animales, como los roedores, entre otros numerosos Muridae, pertenecen a especies comensales y su cantidad importante indicaría más que otra cosa su frecuentación asidua del campamento en busca de los residuos orgánicos abundantes en el basural doméstico.

Pero más importantes para nuestros estudios son los animales cazados y en mayor parte consumidos, entre los cuales están, por una parte, las aves, a menudo grandes como el cormorán o "guanay" (Phalacrocorax bougainvillei) y, por otra parte, los herbívoros. Entre los restos de estos últimos, sólo una pequeña cantidad de artiodáctilos pudieron ser identificados, perteneciendo a camélidos (probablemente Lama guanicoe) y a cérvidos, pero queda un grupo grande de restos de "mamíferos mayores", sin identificación más 
precisa, pero que lógicamente deberían incluir una gran mayoría de herbívoros y muy pocos mamíferos marinos, a juzgar por la cantidad mínima de restos de pinnípedos identificados.

Observamos que los porcentajes de estas diversas categorías difieren, entre el conjunto de los niveles antiguos (N7 a N4) y el de los niveles recientes (N3-N2). Sobre los totales respectivos de 4.438 (N7 a N4) y 7.509 (N3-N2) restos de animales considerados como cazados, las aves son más numerosas al inicio de la ocupación $(83,4 \%)$ que en los niveles recientes $(60,7 \%)$. Al revés, la proporción de los herbívoros+mamíferos mayores alcanza apenas $14 \%$ al inicio, mientras sube a $37 \%$ al final de la ocupación. En cuanto a los mamíferos marinos identificados, su porcentaje queda equivalente $( \pm 2,5 \%)$ en las dos fases. En realidad, la caza de lobos marinos debió limitarse a la captura anecdótica de algunos individuos arponeados o muertos a golpes sobre las rocas costeras, o tal vez recuperados en estado de carroña en las playas.

Estas diferencias en la elección de las presas en ambas fases están sin lugar a duda relacionadas con el modo de ocupación del sitio. Sugieren en todo caso una importancia creciente de la caza terrestre al final de la ocupación.

\section{Los restos vegetales}

Los macrorrestos vegetales identificados por Alexandre Chevalier (Chevalier en Lavallée y Julien 1998:46-61, 2000:67-82, 2003:49-60) son muy escasos pero un poco más abundantes en N3-N2. Fueron recogidos por flotación, bajo forma de semillas (Amaranthus sp., Chenopodium sp., Solanum cf. montanum, etc), cápsulas y muy pequeños fragmentos, carbonizados o no, de plantas silvestres (Sesuvium portulacastrum, Nolana sp.), de cactáceas y de juncos (Scirpus sp.). Sin embargo, en el medio natural circundante abundaban especies vegetales susceptibles de abastecer a los ocupantes del campamento como combustible o materias primas para fabricaciones diversas: algunas especies de árboles tipo acacia para fabricar astas de dardos y arpones, cañas y juncos para elaborar paravientos, cordeles, bolsas, cuerdas, redes y hasta embarcaciones livianas, sin olvidar algunas especies comestibles.

Con el fin de paliar la rareza de los macrorrestos (carporrestos y carbones), se emprendieron análisis de fitolitos. Los primeros resultados han detectado una leve modificación del clima en el nivel N5
( 9.179 cal a.p.): anteriormente en N6 se observa una vegetación de clima más frío y húmedo, con una alternancia de fases húmedas y secas (Chevalier 2008). No tenemos todavía los resultados detallados de estos análisis, pero estas primeras observaciones complementan los datos existentes y fortalecen las hipótesis acerca de una modificación climática sobrevenida entre los dos conjuntos de niveles antiguos (N7 a N4) y recientes (N3-N2).

Además, un dato nuevo e importante sería la presencia detectada en N2 de un fitolito de la calabaza domesticada Cucurbita maxima, de la cual, según Chevalier, sería la ocurrencia más antigua conocida hasta la fecha en Suramérica (Chevalier 2008:156).

\section{Armas y Útiles: El Equipo Técnico}

\section{La industria lítica}

Los niveles inferiores N7 a N4 arrojaron una cantidad muy reducida de industria lítica, con sólo 802 desechos de talla, 22 piezas bifaciales y 16 instrumentos unifaciales. Las puntas bifaciales son de forma triangular o pedunculada, elaboradas en dos materias primas seleccionadas, calcedonia y cuarzo de color blanco (Figura 7). Notamos la ausencia en estos niveles de desechos de talla correspondientes a estas puntas, mientras se vuelven abundantes en los niveles recientes N3-N2. El análisis tecnotipológico fino de este material antiguo está en curso. Solamente hemos notado la similitud de las formas pedunculadas con las de las puntas descubiertas en el campamento Acha-2, cerca de Arica en Chile (Muñoz et al. 1993:31-37), donde constituyen uno de los rasgos diagnósticos del sitio (Muñoz et al. 1993: figura 7), con fechas ${ }^{14} \mathrm{C}$ de $8.900 \pm 150$ y $8.970 \pm 255$ BP (¿sin calibrar?).

Contrastando con los niveles inferiores, el conjunto de los niveles N3-N2 arrojó 23.957 piezas líticas que fueron analizadas por Laurent Klaric (Klaric en Julien y Lavallée 2004:45-59, Klaric en Julien et al. 2005:49-62). Los desechos de talla representan $98,48 \%$ del total, las piezas bifaciales $1,2 \%$ y los instrumentos unifaciales $0,5 \%$. Aparece claramente que el objetivo principal del trabajo de talla era la producción de piezas bifaciales, de la cual toda la cadena operativa de elaboración está representada en el lugar mismo, desde las preformas hasta las puntas terminadas. 346 preformas y puntas, enteras o fracturadas, esta vez con forma lanceolada, 

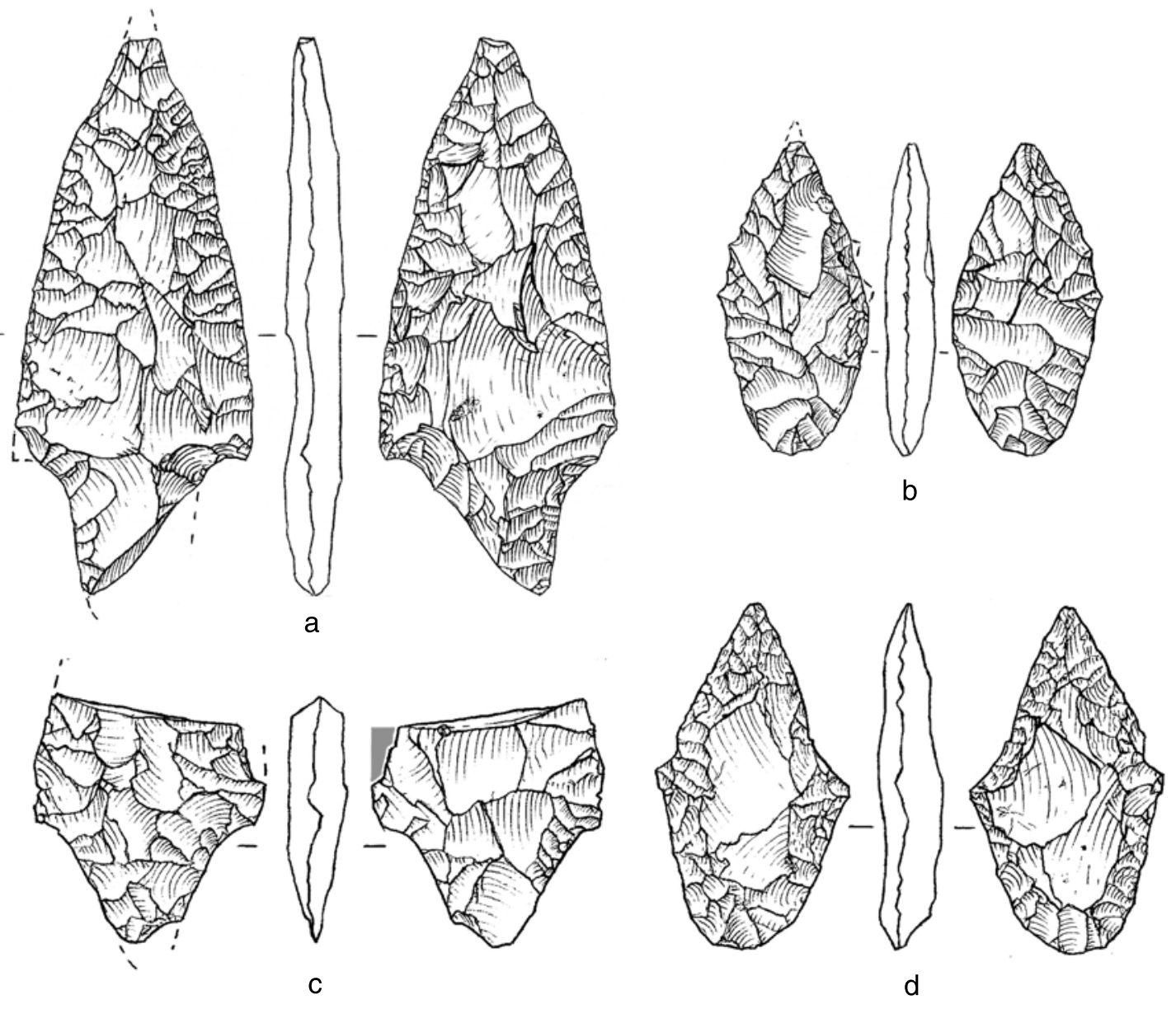

$1 \mathrm{~cm}$
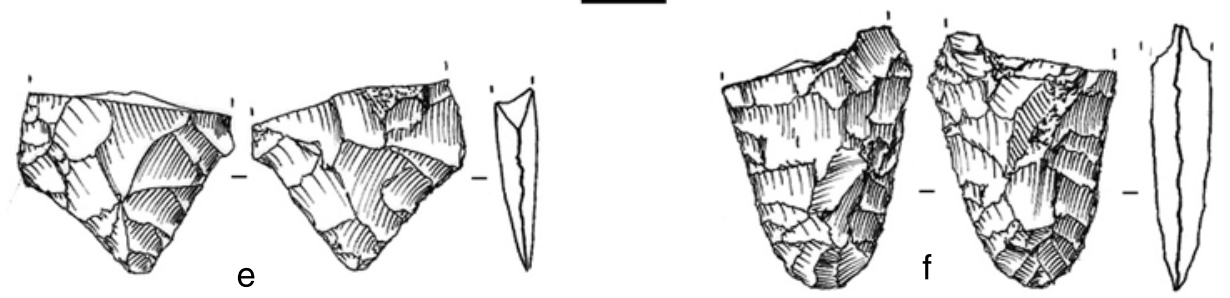

Figura 7. Puntas bifaciales de los niveles N6-N5-N4 de QLB: a (N4), b-c (N5), d-e-f (N6) (Dibujos M. Ballinger y L. Klaric). Bifacial points of levels N6-N5-N4 of QLB: a (N4), bc (N5), d-e-f(N6) (Drawings M. Ballinger and L. Klaric).

fueron identificadas (Figura 8). Se reparten en dos grupos de distinto módulo: un primer grupo corresponde a puntas de $\pm 5 \mathrm{~cm}$ de largo y $1,5 \mathrm{a} 2 \mathrm{~cm}$ de ancho, que podrían haber armado dardos livianos utilizados para la caza terrestre, mientras que un segundo grupo comprende piezas más pesadas midiendo 10 a $12 \mathrm{~cm}$ de largo por $\pm 2,5 \mathrm{~cm}$ de ancho, que podrían haber armado cabezales destacables de arpón utilizados para la captura de peces grandes o de tiburones (¿o también como cuchillos?). Algunas puntas presentan bordes finamente denticulados, obtenidos por un retoque a presión.

Los niveles N3-N2 contenían también 236 instrumentos unifaciales que podemos asociar con actividades domésticas diversas (cortar, raer, raspar, etc.). Se trata generalmente de lascas de forma irregular, resultantes de la talla de piezas bifaciales, y en seguida someramente retocadas. 

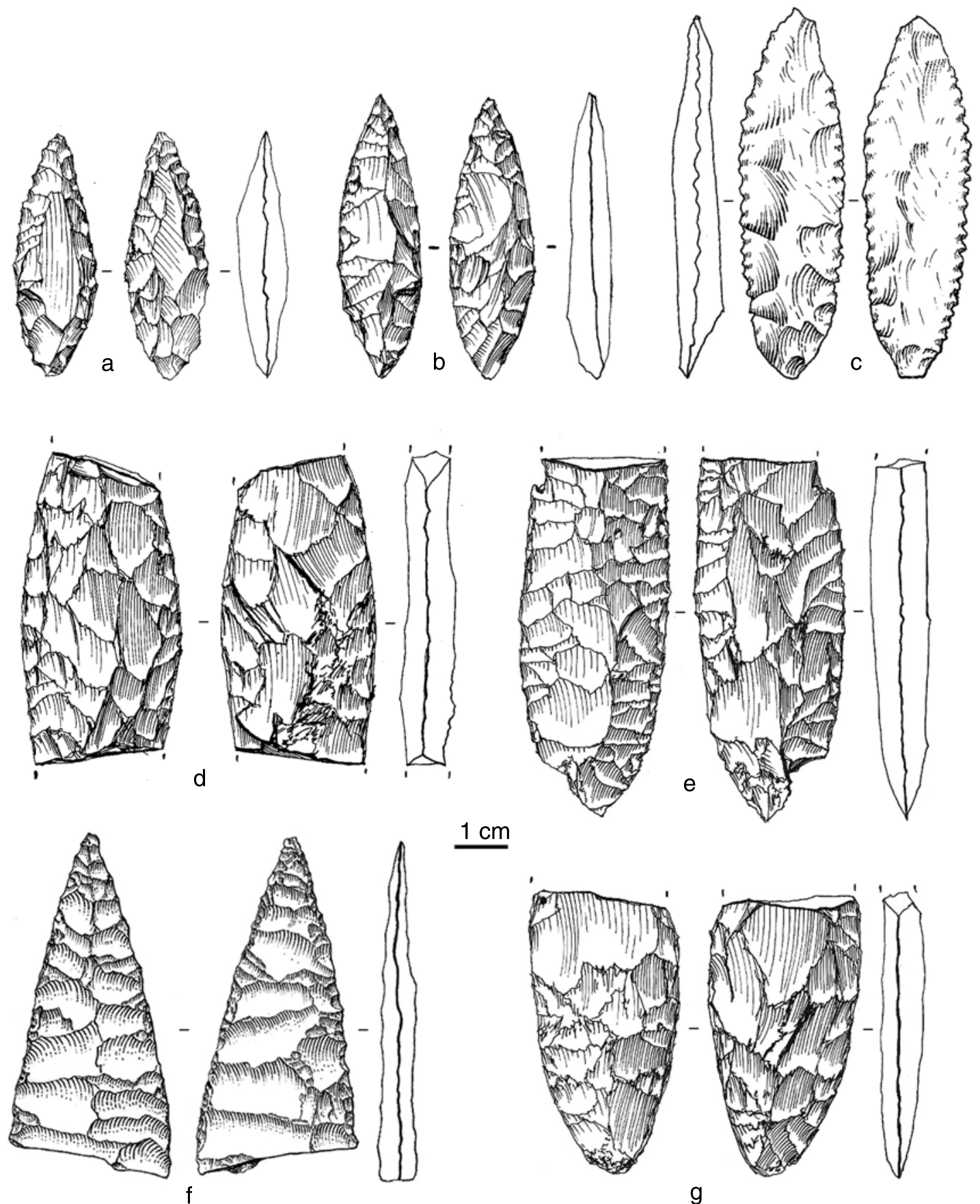

$1 \mathrm{~cm}$
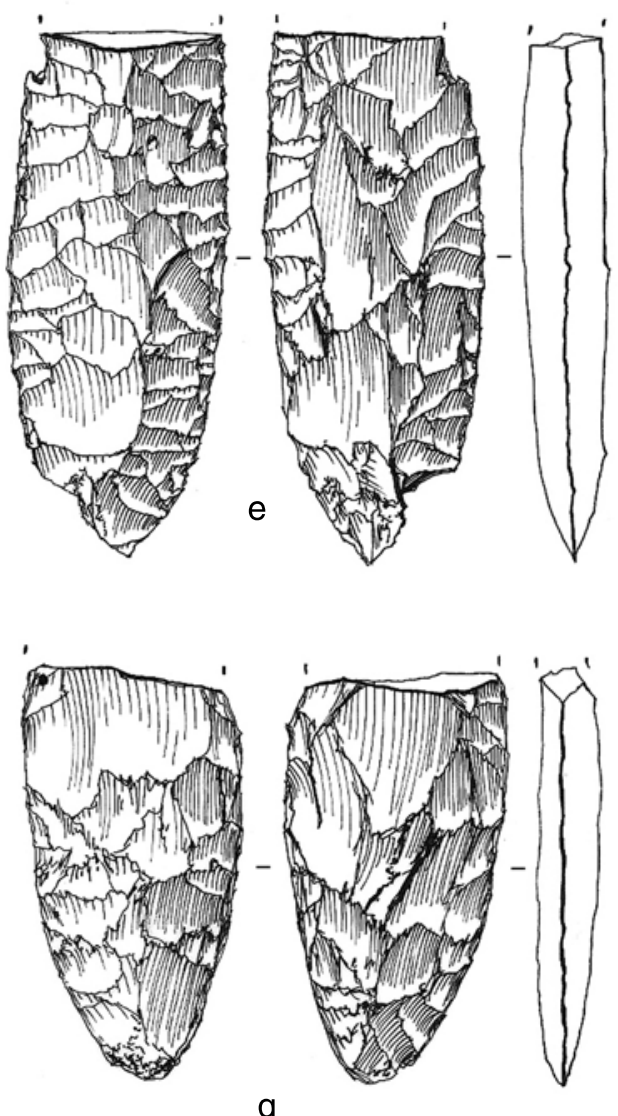

Figura 8. Puntas bifaciales lanceoladas de los niveles N3-N2. Módulo pequeño: (a)-(b)-(c) N2. Módulo grande: (d)-(e) N2), (f ) N3, (g) N2. (Dibujos M. Ballinger, F. Bongni y D. Molez).

Lanceolate bifacial N3-N2 levels. Small module: (a)-(b)-(c) N2. Large module: (d)-(e) N2), (f) N3, (g) N2. (Drawings M. Ballinger, D. F. Bongni and D. Molez). 
En el espacio doméstico del campamento, durante las ocupaciones N3-N2, la mayoría de los desechos de talla se encuentran bajo la forma de lascas de tamaño mediano y minúsculas esquirlas, siendo éstas el mejor indicio de un trabajo efectuado in situ. Las rocas utilizadas (chert y rocas silíceas parduscas) provienen mayormente de los afloramientos silíceos de la Pampa del Platanillo, situada a pocos kilómetros de la QLB y donde se encuentran en superficie centenares de concentraciones de núcleos grandes, lascas y percutores en estas mismas rocas. Los análisis fisicoquímicos realizados por Sébastien Lacombe ${ }^{1}$ han confirmado que esta pampa era el lugar desde el cual se extraían los soportes, primero someramente desbastados en el lugar, luego traídos al campamento para su manufactura final.

Por fin, en todos los niveles se encontraron numerosos guijarros y lascas delgadas extraídas de guijarros, en roca volcánica local, que completaban el ajuar y se utilizaban los primeros como percutores o machacadores, las segundas como instrumentos cortantes.

\section{La industria en hueso y concha}

En el conjunto de los niveles se recuperó una interesante serie de 93 instrumentos en hueso y concha -objetos enteros o fragmentados, esbozos o desechos de fabricación- estudiada por Michèle Julien y Marian Vanhaeren (Vanhaeren en Julien y Lavallée 2004:74-85; Lavallée y Julien 2006: 89-92, 2007: 67-71) (Figura 9). Con la excepción de escasos alisadores o punzones de hueso y de algunas cuentas de concha, todos los objetos están ligados con la pesca. Varios cabezales de arpón en hueso de cetáceo han sido recuperados bajo la forma de fragmentos cilíndricos de $\pm 15 \mathrm{~mm}$ de diámetro; uno de ellos, casi completo, mide 220 $\mathrm{mm}$ de largo. Estas piezas destacables, provistas en su extremidad distal de una barba larga de hueso y a menudo también de una punta lítica, se

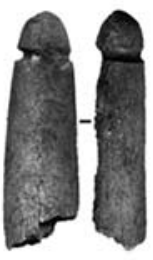

b

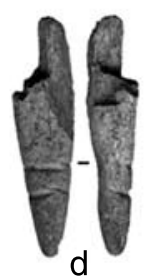

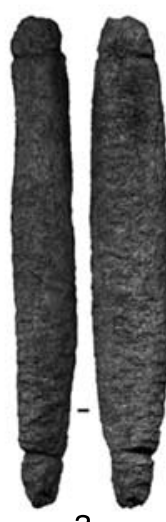

a

$1 \mathrm{~cm}$

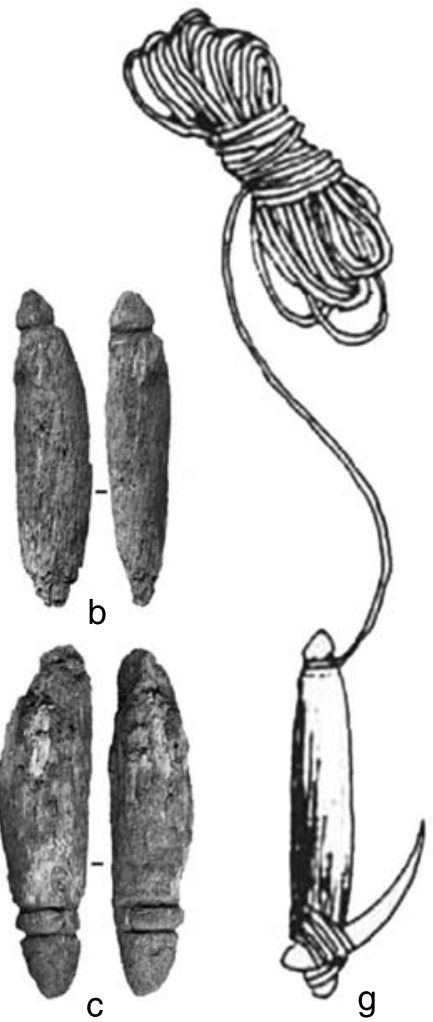

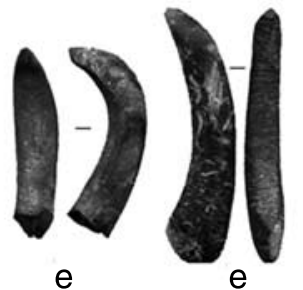

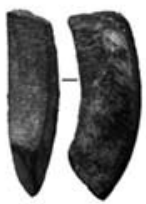

e

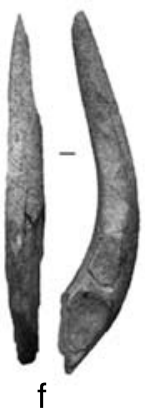

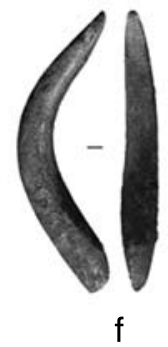

Figura 9. Aparejos de pesca en QLB. (a)-(b)-(c)-(d): pesas de anzuelos compuestos (niveles N2 a N5). (e): fragmentos de barba de anzuelo en concha de $C$. chorus (nivel N2). (f): barbas de anzuelo compuesto en hueso (niveles N5 y N6). (g): modelo de anzuelo compuesto (Llagostera 1989:63, fig. 2).

Fishing gear in QLB. (a)-(b)-(c)-(d): hooks weights compounds (N2 to N5 levels). (e): beard fragments shell hook in C. chorus (at N2). (f): noses of composite bone fishhook (N5 and N6 levels). ( $g$ ) model of fishook compound (Llagostera 1989:63, fig. 2). 
utilizaban probablemente para la captura de los peces más grandes y/o de los mamíferos marinos. Por otra parte, están presentes en todos los niveles elementos de anzuelos compuestos: 18 barbas - largas puntas encorvadas de hueso o elementos más compactos extraídos del borde abultado de valvas de Choromytilus chorus- y 13 pesas alargadas en hueso de Otaridae o en concha, que presentan en una extremidad ranuras para fijar la cuerda y en la otra una escotadura oblicua para ligar la barba. Observamos que los objetos elaborados en concha sólo aparecen en los niveles recientes N3-N2. Todos se encontraron aislados en la excavación, faltando los elementos vegetales, astiles y cuerdas, debido a las malas condiciones de conservación (existencia de un escurrimiento subterráneo). Se agregan a estos instrumentos finamente elaborados algunas pesas de cuerda en hueso, de factura más tosca pero que llevan siempre una ranura en una de sus extremidades. Por fin, varias piezas abandonadas en curso de su manufactura, como esbozos y preformas de barbas, se encontraron junto a pulidores en beach-rock muy rugoso que presentan profundas ranuras de pulimento.

Observamos que, desde el inicio de la ocupación, toda la cadena operativa de fabricación de estos diversos aparejos sofisticados está representada en el campamento. La diversidad del equipo de pesca, la etoecología diferenciada de las especies de peces y sus tamaños medios calculados por Philippe Béarez sobre los otolitos, confirman la diversidad de los modos de captura, con cuerda, con redes o con arpón, desde la orilla o desde esquifes livianos pero capaces de traspasar la surf-zone donde rompen las olas.

\section{Espacio Doméstico y Estructuras de Hábitat}

Al término de las excavaciones en 2007 se pudo estimar la superficie total del área doméstica en unos 25/30 metros de diámetro.

$\mathrm{Al}$ inicio de la primera fase de ocupación (nivel N7) los ocupantes recién llegados instalan su campamento sobre la pendiente arenosa, muy cerca del pantano o laguna de agua dulce estancada cuyo límite, en aquella época, llega hasta la mitad del espacio que separa hoy día el afloramiento rocoso del talweg. Una primera habitación está implantada al noreste del área (en los metros DE 5-6), de la cual están todavía visibles cinco bloques de roca delimitando un espacio semicircular de
2,5/3 m de diámetro, abierto hacia el talweg. En el exterior de la estructura, depósitos arqueológicos muy esparcidos sobre la pendiente consisten en algunas manchas de cenizas y delgadas capas de conchas, compuestas casi exclusivamente de valvas de Choromytilus chorus y Perumytilus purpuratus, en concentraciones separadas. A esta primera estadía sucede una corta interrupción de la ocupación, marcada por un depósito eólico de arena, y en seguida las instalaciones más seguidas e intensas de la fase 1 , que corresponden a los niveles N6, N5 y N4. El sedimento viene cargándose en conchas (esencialmente Mesodesma donacium) y otros restos orgánicos. A lo largo del tiempo, varias estructuras circulares son instaladas, siempre de la misma dimensión, con el fondo a veces levemente cavado en el suelo y cuyas huellas a menudo se recubren una a la otra. Tienen en común un espacio interior casi libre de vestigios con la excepción de restos de uno o dos fogones simples (planos), y delgadas acumulaciones periféricas de conchas y otros desperdicios (Figura 10). Testimonian la edificación probable de estructuras livianas destinadas a protegerse del sol y del viento. Lo esencial de las actividades se desarrollaba en el exterior, donde numerosas áreas de actividad pudieron ser evidenciadas: en N6, los sectores cercanos a la laguna parecen haber sido reservados al tratamiento (¿desconchamiento y secado?) de las machas, y el sedimento profundamente cargado en cenizas atestigua la recurrencia de combustiones en este sector. En N5 y N4, el campamento se extiende más arriba en la pendiente, donde varias áreas de actividad bien delimitadas parecen haber sido dedicadas a la preparación y el consumo de centenares de cangrejos y peces, y otras a la fabricación de aparejos de pesca en hueso y concha.

Después de una nueva y larga interrupción de la ocupación (observable en la secuencia de los fechados ${ }^{14} \mathrm{C}$, ver Tabla 1), el lugar es nuevamente ocupado, y la intensidad de las ocupaciones de la fase 2 (niveles N3-N2) se nota en la textura del sedimento fuertemente cargado en materias orgánicas, cenizas y carbones, así como por el grosor de las concentraciones de Concholepas concholepas. Su acumulación hizo que se acentúe la pendiente del piso ocupacional, lo que a su vez llevó a los ocupantes a tratar de nivelar el suelo mediante una especie de terrazas hechas de bloques de piedra y conchas. En esta época, el nivel del agua dulce había bajado y la orilla ha retrocedido en varios metros, permitiendo 
que las áreas de actividad se extiendan más hacia el talweg. Con la excepción de la implantación de un paraviento marcada por un arco de piedras, los vestigios de habitaciones se divisan menos fácilmente que en los niveles anteriores. Se notan, sin embargo, en varios lugares áreas circulares de 2,5 a $3 \mathrm{~m}$ de diámetro, marcados por gruesos depósitos o cordones de materias carbonizadas y a veces asociados con algunos grandes bloques rocosos. Estas unidades habitacionales parecen haber sido ocupadas durante mucho más tiempo que las de la primera fase de ocupación. Al exterior de ellas, varios fogones con borde de piedras o de conchas calcinadas testimonian repetidas operaciones de cocina o cocción de moluscos. Otras acumulaciones de conchas, a menudo monoespecíficas (Concholepas concholepas o Choromytilus chorus) están esparcidas en la pendiente, a las cuales se suman varias concentraciones de desechos líticos que testimonian un trabajo de talla realizado in situ, lo que no se observó en la fase 1.

\section{Dos inhumaciones en el campamento}

En 2005, en el fondo del nivel N3 y casi al centro del espacio doméstico (metros KL 4-5), apareció el esqueleto de un individuo de sexo masculino, depositado en posición flexionada sobre el lado derecho, sin ningún tipo de envoltura ni ofrenda. Los restos óseos, casi completos pero en un pésimo estado de conservación, fueron excavados por Aldo Bolaños y luego estudiados en el IFEA por Tania Delabarde (Julien et al. 2005:35-37; Delabarde en Lavallée y Julien 2007:61-66). Se trata del esqueleto de un adulto joven en el cual (pelvis y miembros) se registraron varias lesiones probablemente debidas a un episodio de carencia de orden nutricional. Pero lo que llama la atención es que el conjunto craneofacial presenta modificaciones anatómicas aparentemente ligadas a una actividad específica de la mandíbula: sobre los molares del maxilar, un desgaste oblicuo hacia afuera y, sobre uno de los

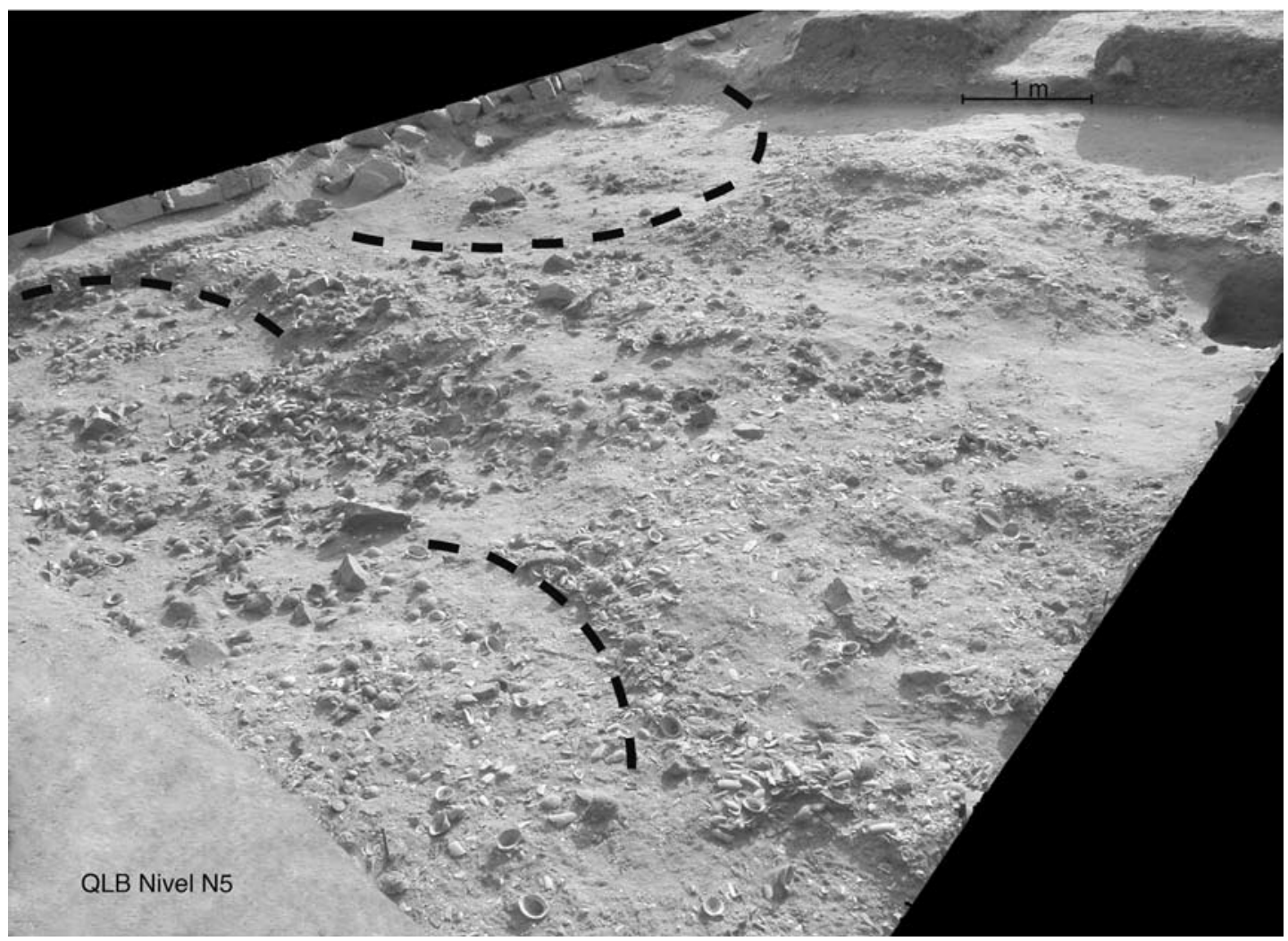

Figura 10. Vista oblicua del nivel N5, parte sur $\left(48 \mathrm{~m}^{2}\right)$. Varios cordones de conchas delimitan áreas circulares relativamente libres de vestigios, que interpretamos como los fondos de estructuras habitacionales de entre 2,5 y $3 \mathrm{~m}$ de diámetro.

$N 5$ level oblique view, southern $\left(48 \mathrm{~m}^{2}\right)$. Several strands of shells define circular areas relatively free of traces, which we interpret as funds housing structures between 2.5 and $3 \mathrm{~m}$ in diameter. 
premolares izquierdos superiores, la presencia de una ranura sobre la superficie oclusal. Esos estigmas sugieren el paso repetido de un elemento filiforme entre los dientes, jalado hacia afuera y abajo. De tal manera que los molares y premolares parecen haber sido utilizados como instrumentos; tal actividad mecánica de la mandíbula puede ser el origen de las lesiones observadas sobre el cóndilo. Eso permite pensar que la mandíbula se utilizó para triturar y transformar una materia vegetal como fibras de junco o de cactus, utilizadas para la fabricación de cuerdas, redes, bolsas, etc. Esta inhumación no pudo fecharse directamente (ausencia de colágeno), pero su posición debajo de los depósitos del nivel N3, estos mismos sin huella de perturbación, indicaría una edad entre 8.000 y 7.500 a.p.

En 2007, al final de la excavación del primer nivel de ocupación N7, se notó en el ángulo SW (metros M7-8) una interrupción de los depósitos de conchas que dejaban lugar a una zona de arena estéril de $5 / 6 \mathrm{~cm}$ de grosor, cubriendo una estructura elíptica conformada por siete grandes bloques de piedra. En el espacio interior observamos elementos muy fragilizados de un esqueleto humano que parecían corresponder a la mitad superior de un cuerpo y, fuera del óvalo de piedras, se distinguía un conjunto de falanges. Considerando la importancia de este descubrimiento, decidimos interrumpir la exploración, proteger cuidadosamente los restos mediante una cobertura de arena de $2 \mathrm{~m}$ de grosor y postergar su explotación para una próxima temporada, la cual se desarrolló en 2009.

Los restos articulados de un individuo adulto completo se registraron en una fosa poco profunda, depositado en posición hiperflexionada sobre el lado izquierdo. El difunto estaba completo y articulado, y ningún elemento óseo se encontró fuera del volumen del cuerpo, lo que sugiere la presencia inicial de un elemento envolviendo el cuerpo. Al final se colocó un bloque grande de piedra sobre las piernas dobladas. No había ningún ajuar funerario, pero sobre los dos bloques de piedra más cercanos a la cabeza se observaron huellas de colorantes negro y rojo. Efectivamente, observamos manchas negras al nivel del parietal izquierdo y una muestra fue tomada para determinar si se trata de un proceso tafonómico (descomposición) o de un tratamiento funerario específico (coloración).

El estudio antropológico se desarrolló in situ, debido al pésimo estado de conservación del esqueleto. El estudio de los caracteres craneales y del proceso de erupción dental permitió a Tania
Delabarde determinar su sexo masculino y atribuirle una edad de aproximadamente 25 años. Ella observó también unas lesiones de tipo hiperostosis porótica al nivel de la sutura frontonasal y de las órbitas, que podrían resultar de una infección o carencia alimentaria (Delabarde et al. 2009).

Los análisis radiocarbónicos de algunas muestras de hueso y diente están todavía en curso, pero las fechas obtenidas para el nivel N7 -9.411 y $9.581 \mathrm{cal}$. a.p.- y el hecho que la observación de los mosaicos fotográficos de los niveles superiores N6 y N5 no ha revelado ninguna perturbación de los depósitos en los metros L-M 7-8, indicarían entonces que el entierro se remonta al final de la ocupación de N7, hacia aproximadamente $9.500 \mathrm{cal}$. a.p., lo que lo ubica entre los más antiguos restos humanos conocidos en el área andina.

\section{Conclusión}

Queda por resolver un problema mayor, que es el del ritmo y duración de las estadías en QLB a lo largo de cada una de las dos fases de ocupación.

Los análisis esclerocronológicos llevados a cabo por Matthieu Carré sobre una serie de valvas arqueológicas de Mesodesma donacium procedentes de los niveles N6 a N2 (no se analizaron muestras de N7) permitieron evaluar la fecha de su muerte (Carré 2007; Carré et al. 2005; 2009). Demuestran que la colecta de la especie siempre fue una actividad estacional, pero que existen diferencias entre las temporadas de colecta, del Holoceno Temprano (N6 a N4) al Holoceno Medio (N3-N2). Durante la primera fase, la temporada de colecta dura casi ocho meses (octubre a mayo), con un máximo de actividad en enero, durante el invierno austral, o sea fuera del período de actividad de las lomas. Durante la segunda fase, la colecta no parece durar más que cinco meses, entre setiembre y enero, con un máximo de actividad en octubre, o sea, al momento de mayor desarrollo de las lomas. Parece poco verosímil que las pocas variaciones climáticas observadas entre el inicio y el final de la ocupación de QLB puedan explicar esta diferencia entre los períodos de colecta. En cambio, y como ya hemos mencionado, queda la posibilidad de que la extensión de las playas arenosas haya sido reducida como consecuencia de la subida del nivel oceánico durante el Holoceno Medio, lo que podría explicar que la colecta de $M$. donacium haya sido reducida y poco a poco reemplazada por la de Concholepas concholepas. 
Sin embargo, podemos también evocar un cambio cultural, como parecen reflejarlo las diferencias observadas entre los conjuntos líticos de las dos fases de ocupación: tipos diferentes de puntas bifaciales, también el hecho que toda la cadena operativa de fabricación esté en un caso atestada (fase 2) pero inexistente en la otra (fase 1). De un tal cambio cultural podría también ser testigo una modificación de la naturaleza, de la intensidad y tal vez de la duración de las actividades realizadas en QLB. Así, las ocupaciones del Holoceno Temprano (fase 1) podrían corresponder a breves ocupaciones -algunos días hasta algunas semanas- pero repetidas a lo largo del año, especialmente entre octubre y mayo (período de mayor colecta de $M$. donacium). En esta perspectiva, el sitio QLB parecería corresponder más a un "paradero logístico" que a un hábitat semipermanente. La brevedad probable de las estadías durante esta fase 1, aun entre octubre y mayo (cuando las lomas están secas), y la drástica baja de actividad de colecta de machas observada por Matthieu Carré durante el invierno austral (cuando las lomas alcanzan su mayor desarrollo), podrían explicar la proporción baja de los restos de herbívoros en los niveles N7 a N4: cuando se colectaba la mayor cantidad de machas, el momento no era favorable para la caza terrestre, aun cuando era posible capturar aves. La cantidad reducida de industria lítica y especialmente de los instrumentos bifaciales terminados podría entonces explicarse, lo mismo que el número y la disposición de los acondicionamientos en el campamento, por emplazamientos que cambian y se superponen al ritmo de las salidas y llegadas repetidas de los ocupantes.

En cambio, durante el Holoceno Medio (fase 2), parece que el sitio conoce una ocupación mucho más larga e intensa durante varias semanas o meses consecutivos, con acondicionamientos más perennes. Las actividades de talla lítica efectuadas in situ son numerosas y abundantemente representadas por concentraciones de desechos, útiles domésticos y puntas bifaciales (esa vez foliáceas). Recordamos que, durante el Holoceno Medio, las condiciones climáticas se han vuelto más húmedas y más favorables y las lomas más activas. La caza terrestre se practica entonces de manera activa y proporciona una parte apreciable de la alimentación.

Los cambios ocurren entre las ocupaciones N4 y N3, separadas por un estrato estéril y un "silencio" en la secuencia de los fechados radiocarbónicos.
Dichos elementos sugieren que la QLB fue, por una razón aún desconocida, abandonada al final de $\mathrm{N} 4$, hasta la llegada de un nuevo grupo de ocupantes, del cual no sabemos todavía si se trata de los descendientes de los primeros o de pobladores de otro origen. Hasta la fecha, ningún indicio material había venido sustentar la hipótesis de una llegada desde la sierra andina cuando, al revés, la perfecta adaptación al medio marítimo y el manejo de un ajuar sofisticado de pesca, observados desde el inicio de la ocupación, más bien nos llevaban a plantear la hipótesis de una llegada temprana desde el norte a lo largo de la costa, hipótesis propuesta por Fladmark (1979; Lavallée, Béarez et al. 1999:414). Hoy en día, el descubrimiento en 2007 de puntas pedunculadas o romboidales con aletas en los niveles N6, N5 y N4 (ausentes en sitios peruanos más septentrionales), y su semejanza con puntas encontradas en el extremo norte de Chile, por una parte confirma la estrecha relación del campamento QLB con sitios chilenos de la cultura Chinchorro como Acha-2. Por otra parte, la comparación de estas puntas de sitios costeros con puntas del mismo tipo procedentes de dos sitios chilenos serranos, Patapatane y Las Cuevas, de equivalente antigüedad (Arriaza 1995:41), y la presencia de un fragmento de concha de Choromytilus chorus en Patapatane y de un diente de tiburón en Las Cuevas (Santoro y Núñez 1987:70-71) hacen más que sugerir contactos entre la sierra y la costa. Quedan sin embargo muchos interrogantes que contestar antes de poder trazar los desplazamientos de los grupos humanos y reconstituir su trayectoria inicial, de la sierra a la costa o al revés.

Agradecimientos: La investigación en Quebrada de los Burros fue auspiciada por el Ministerio de Relaciones Exteriores de Francia y por el CNRS (Centro Nacional de Investigación - Francia). Se agradece a todos los que participaron desde 1995 al Proyecto PERÚ-SUR. Además de los autores del presente texto, que formaron desde el inicio el equipo de campo o efectuaron los análisis de laboratorio, nos ayudaron durante varias temporadas los colegas o estudiantes peruanos Manuel Aguirre, Desidee Alcalde, Camilo Dolorier, Carlos Farfán, Claudia Grimaldo, Roxana Paucar, Julissa Ugarte y Rocio Villar, y los colegas franceses Robert Chenorkian, Georges Clément y Valérie Schidlowsky. Agradecemos calurosamente a nuestra codirectora Dra. Denise Pozzi-Escot y al Lic. Jesús 
Gordillo, arqueólogo del INC de Tacna, gracias al cual entramos por primera vez, en 1994, en esta quebrada mágica. Queremos también agradecer de manera particular al Lic. Luis Flores quien revisó de manera perfecta la traducción al castellano y aseguró con una máxima paciencia el ajuste de nuestro texto a las pautas de esta revista. Se extiende el agradecimiento a los evaluadores anónimos de Chungara por sus comentarios y observaciones. Todas las omisiones y errores son nuestros.

\section{Referencias Citadas}

Arriaza, B. 1995. Chinchorro bioarchaeology: Chronology and mummy seriation. Latin American Antiquity 6:35-55.

Béarez, P. 2000. Archaic fishing at Quebrada de los Burros, southern coast of Peru. Reconstruction of fish size using otoliths. Archaeofauna 9:29-34.

Bronk Ramsey, C. 2007. Oxcal Program, V. 40, Radio-Carbon Accelerator Unit, University of Oxford, UK; https://c14.arch. ox.ac.uk/oxcal.html

Carré, M. 2007. El mes de recolección de la macha (Mesodesma donacium) determinado por sus líneas de crecimiento: aplicaciones arqueológicas. Bulletin de l'Institut Français d'Etudes Andines 36:299-304.

Carré, M., I. Bentaleb, D. Blamart, N. Ogle, F. Cárdenas, F. Zevallos, R. M. Kalin, L. Ortlieb, y M. Fontugne 2005. Stable isotopes and sclerochronology of the bivalve Mesodesma donacium: Potential application to Peruvian paleoceanographic reconstructions. Palaeo 228:4-25.

Carré, M., L. Klaric, D. Lavallée, M. Julien, I. Bentaleb, M. Fontugne y O. Kawka 2009. Insights into Early Holocene hunter-gatherer mobility on the Peruvian Southern Coast from mollusk gathering seasonnality. Journal of Archaeological Science 36:1073-1078.

Chevalier, A. 2008. Early Holocene human adaptation in the Central Andes: What the phytoliths can tell us. En Matices Interdisciplinarios en Estudios Fitolíticos y de otros Microfósiles, editado por M.A. Korstanje y M. del P. Babot, pp. 149-160. BAR International Series S1870.

Delabarde, T., D. Lavallée, A. Bolaños y M. Julien 2009. Descubrimiento de un entierro del Arcaico Temprano en el sur del Perú. Bulletin de l'Institut Français d'Etudes Andines 38:939-946.

Fladmark, R. 1979. Routes: Alternative migration corridors for Early Man in North America. American Antiquity 44:55-69.

Fontugne, M., P. Usselmann, D. Lavallée, M. Julien y C. Hatté 1999. El Niño variability in the Coastal Desert of Southern Peru during the Mid-Holocene. Quaternary Research 52:171-179.

Julien, M. y D. Lavallée 2004. Projet Pérou-Sud. Rapport scientifique annuel. CNRS-IFEA (mimeografiado).

Julien, M., D. Lavallée y A. Bolaños 2005. Projet Pérou-Sud. Rapport scientifique annuel. CNRS-IFEA (mimeografiado).

Lavallée, D. 2003. The first peopling of the South Pacific American Coast during the Pleistocene/Holocene Transition. A case study: The Prehistoric Campsite of Quebrada de los Burros (Tacna, Perú). En Where the South Winds Blows. Ancient Evidence of
Paleo South Americans, editado por L. Miotti, M. Salemme M. y N. Flegenheimer, pp. 17-20, Center for the Study of the First Americans, Corvallis.

- - - 2005. La transition Pléistocène/Holocène et les premiers peuplements humains du littoral sud-pacifique américain. En Peuplements Humains et Variations Environnementales au Quaternaire, editado por A. Tuffreau, pp. 147-150, BAR International Series 1352.

Lavallée, D. y M. Julien 1998. Projet Pérou-Sud-Rapport scientifique annuel. CNRS-IFEA (mimeografiado).

- - - 2000. Projet Pérou-Sud-Rapport scientifique annuel. CNRS-IFEA (mimeografiado).

- _ - 2003. Projet Pérou-Sud-Rapport scientifique annuel. CNRS-IFEA (mimeografiado).

- - - 2006. Projet Pérou-Sud - Rapport scientifique annuel. CNRS-IFEA (mimeografiado).

- - - 2007. Projet Pérou-Sud-Rapport scientifique annuel. CNRS-IFEA (mimeografiado).

Lavallée, D., P. Béarez, A. Chevalier, M. Julien, P. Usselmann y M. Fontugne 1999. Paleoambiente y ocupación prehistórica del litoral extremo-sur del Perú. Las ocupaciones del Arcaico en la Quebrada de los Burros y alrededores (Tacna, Perú). Boletín de Arqueología PUCP 3:393-416.

Lavallée, D., M. Julien, P. Béarez, P. Usselmann, M. Fontugne y A. Bolaños 1999. Pescadores-recolectores arcaicos del extremo-sur peruano. Excavaciones en la Quebrada de los Burros (Tacna, Perú). Bulletin de l'Institut Français d'Etudes Andines 28:13-52.

Llagostera, A. 1989. Caza y pesca marítima 9.000 a 1.000 a.C. En Culturas de Chile. Prehistoria: Desde sus Orígenes hasta los Albores de la Conquista, editado por J. Hidalgo, V. Schiappacasse, H. Niemeyer, C. Aldunate e I. Solimano, pp. 57-79. Editorial Andrés Bello, Santiago.

Muñoz, I., B. Arriaza y A. Aufderheide (eds.). 1993. Acha-2 y los Orígenes del Poblamiento Humano en Arica. Ediciones Universidad de Tarapacá, Arica.

Reimer, P.J., M.G. Baillie, E. Bard, A. Bayliss, J.W. Beck, C.J.H. Bertrand, P.G. Blackwell, C.E. Buck, G.S. Burr, K.B. Cutler, P.E. Damon, R.L. Edwards, R.G. Fairbanks, M. Friedrich, T.P. Guilderson, A.G. Hogg, K.A. Hughen, B. Kromer, G. McCormac, S. Manning, C.B. Ramsey, R.W. Reimer, S. Remmele, J.R. Southon, M. Stuiver, S. Talarco, F.W. Taylor, J. van der Plicht y C.E. Weyhenmeyer 2004. Int. Cal 04 Terrestrial radiocarbon age calibration, 0-26 Cal KyR BP. Radiocarbon 46:1029-1058. 
Sandweiss, D.H. 2003. Terminal Pleistocene through MidHolocene archaeological sites as paleoclimatic archives for the Peruvian coast. Palaeo 194:23-40.

Santoro, C. y L. Núñez 1987. Hunters of the dry puna and the salt puna in northern Chile. Andean Past 1:57-109.
Usselmann, P., M. Fontugne, D. Lavallée, M. Julien y C. Hatté 1999. Estabilidad y rupturas dinámicas en el Holoceno de la costa surperuana: el valle de la Quebrada de los Burros (Departamento de Tacna). Bulletin de l'Institut Français d'Etudes Andines 28:1-11.

\section{Nota}

1 Visiting scholar, Universidad de Berkeley (USA), y UMR 5608, Maison de la Recherche, Toulouse, France. 
